\title{
Synergistic Inhibition of Natural Honey and Potato Starch and their Correlation with Diastase Number and Sugar Content against Klebsiella pneumoniae ATCC 27736
}

\author{
Moussa Ahmed ${ }^{1 *}$, Noureddine Djebli ${ }^{2}$, Saad Aissat ${ }^{1}$, Salima Bacha ${ }^{1}$, Abdelmalek Meslem $^{1}$ and Baghdad Khiati ${ }^{1}$ \\ ${ }^{1}$ Institute of Veterinary Sciences, Ibn-Khaldoun University, Tiaret, Algeria \\ ${ }^{2}$ Departments of Biology, Faculty of Sciences, Mostaganem University, Algeria
}

\begin{abstract}
Alternative therapy for Klebsiella pneumoniae eradication from natural products is gaining much attention. The aim of the present study was to determine the physico-chemical parameters and the synergistic effects of six natural honeys in combination with potato starch against pathogenic Klebsiella pneumoniae. Physico-chemical parameters, such as fructose, glucose, maltose, sucrose, Diastase number and Hydroxymethylfurfural (HMF) content were measured. The antibacterial activity was tested using the well-agar diffusion assay. The fructose, glucose, maltose and sucrose values range between $25.20-37.81 \%, 21.45-30.95 \%, 4.72-78.45 \%$ and $0.00-0.68 \%$. Hydroxymethylfurfural (HMF) content shows values between 3.8 and $78.4 \mathrm{mg} / \mathrm{kg}$, diastase values were between 7.3 and 22.1 Schade. The zone inhibition diameter (ZID) for the six honey samples without starch against Klebsiella pneumoniae ranged between 18 and $24 \mathrm{~mm}$. When starch was mixed with honey and then added to well, a zone inhibition increase diameter (ZIID) 25 and $32 \mathrm{~mm}$. The percentage increase (PI \%) was noticed with each variety and it ranged between 25 and $66.66 \%$. Positive correlation has been established between the zone increase of inhibition and the fructose, glucose and Diastase number. Negative correlation has been established between the zone increase and the sucrose. The results of the present study showed that the combination effects of honey and potato starch were predominately synergistic. The in vitro synergistic activity of honey and potato starch against bacteria is reported here for the first time.
\end{abstract}

Keywords: Synergistic; Honey; Potato starch; Diastase number; Sugar content

\section{Introduction}

The overuse of antimicrobial agents is one of the major factors in the development and spread of drug resistance in organisms, as well as in colonization and infection by drug-resistant organisms. Klebsiella pneumoniae is a successful opportunistic pathogen and has been associated with various ailments such as urinary tract infection, osteomyelitis, meningitis, septicemia, respiratory tract infection and diarrhea [1,2]. Treatment of $K$. pneumoniae infections has become increasingly difficult because of the predominance of multipleantibiotic-resistant strains $[3,4]$. Thus, it is urgent need to find out new antimicrobial agents. Natural products traditionally have played an important role in drug discovery and were the basis of most early medicines [5]. Honey is a natural product that is used for its antibacterial activity [6-10]. Honey, produced by the honeybee, is a natural supersaturated sugar solution, which is mainly composed of a complex mixture of carbohydrates [11]. Carbohydrates, the main constituents of honey, are produced by honey-bees from nectar sucrose, which is transformed through the action of different enzymes, notably, diastase ( $\alpha$ - and $\beta$-amylase), invertase ( $\alpha$-glucosidase), glucose-oxidase, catalase and acid phosphatase, which come from nectar sources, salivary fluids and the pharyngeal gland secretions of the honeybee [12]. Amylase in honey mainly originates from the salivary secretions of honeybees, which was concluded based on the presence of amylase in honey produced by sugar-fed honeybees [13]. Diastase (mixture of amylases) is used to evaluate honey freshness and heat treatment. Diastase is largely from honeybees with a contribution from pollen and nectar [14]. The $\alpha$-amylase splits the starch chain randomly, producing dextrin, and the $\beta$-amylase splits the reducing sugar maltose from the ends of the starch chain. According to the Honey Quality and International Regulatory Standards, from the International Honey Commission, the diastase activity must not be less than or equal to 8, expressed as diastase number (DN). DN in Schade scale, which corresponds to the Gothe scale number, is defined as g starch hydrolyzed in $1 \mathrm{~h}$ at $40^{\circ} \mathrm{C}$ per $100 \mathrm{~g}$ honey. HMF (5-hydroxymethylfurfuraldehyde) measurement is used to evaluate the quality of honey; generally not present in fresh honey, its content increases during conditioning and storage [15]. The European Union [16] (EU Directive 110/2001) fixed a HMF limit in honey of $40 \mathrm{mg} / \mathrm{kg}$. In this study, we evaluated the antibacterial activity of six varieties of honey and their combination with potato starch in correlation with diastase number ( $\alpha$ - amylase), and sugar content.

\section{Materials and Methods}

\section{Honey sample}

Six natural honey samples from Algeria were collected. All samples were collected directly from beekeepers in 2011-2012 and stored in the dark at $4^{\circ} \mathrm{C}$.

\section{Preparation of the stock starch solution}

The stock starch solution was prepared by dissolving $0.5 \mathrm{~g}$ of dried soluble starch in deionised water in a volumetric flask. After heating and stirring the solution for approximately ten minutes, starch was completely dissolved, and the volumetric flask was filled with deionized water to the mark.

\section{Physicochemical analysis}

All physicochemical tests were performed in triplicate.

*Corresponding author: Moussa Ahmed, Institute of Veterinary Sciences, IbnKhaldoun University, Tiaret, Algeria, Tel: 213 65234059; Fax: 213 65234059; E-mail:moussa7014@yahoo.fr

Received December 08, 2012; Accepted December 18, 2012; Published December 19, 2012

Citation: Ahmed M, Djebli N, Aissat S, Bacha S, Meslem A, et al. (2012) Synergistic Inhibition of Natural Honey and Potato Starch and their Correlation with Diastase Number and Sugar Content against Klebsiella pneumoniae ATCC 27736. Nat Prod Chem Res 1:102. doi:10.4172/2329-6836.1000102

Copyright: ( $) 2012$ Ahmed M, et al. This is an open-access article distributed unde the terms of the Creative Commons Attribution License, which permits unrestricted use, distribution, and reproduction in any medium, provided the original author and source are credited. 
Citation: Ahmed M, Djebli N, Aissat S, Bacha S, Meslem A, et al. (2012) Synergistic Inhibition of Natural Honey and Potato Starch and their Correlation with Diastase Number and Sugar Content against Klebsiella pneumoniae ATCC 27736. Nat Prod Chem Res 1:102. doi:10.4172/2329-6836.1000102

Page 2 of 4

Determination of HMF was made according to the Winkler [17], method where, to aliquot parts of a honey solution, solutions of p-toluidine and barbituric acid were added and the resultant color measured against a blank in $1 \mathrm{~cm}$ cuvettes at $550 \mathrm{~nm}$. The diastase activity was determined photometrically by the Phadebas method [18]. The results are expressed as a diastase number $(\mathrm{DN})$ in Gothe or Schade units. One unit corresponds to the enzyme activity of $1 \mathrm{~g}$ of honey, which can hydrolyse $0.01 \mathrm{~g}$ of starch in $1 \mathrm{~h}$ at $40^{\circ} \mathrm{C}$ and $\mathrm{pH}$ 5.2. The diastase activity, expressed as $\mathrm{DN}$ or diastase number, was calculated from the absorbance measurements using Eqs. (1) and (2) for high (8-40 diastase units) and low (up to 8 diastase units) activity values, respectively:

\section{$\mathrm{DN}=28.2 \times \Delta \mathrm{A} 620-2.64(1)$}

\section{$\mathrm{DN}=35.2 \times \Delta \mathrm{A} 620-0.46(2)$}

Sugar spectra (fructose, glucose, sucrose and maltose) were identified and determined by Bogdanov [19] for di- and oligosaccharides using high performance liquid chromatography (HPLC).

\section{Antibacterial susceptibility test}

Bacterial culture and inoculum preparation: Pure culture of Klebsiella pneumoniae ATCC 27736 was obtained from the Department of Biology, Faculty of Sciences, Mostaganem University, Algeria. The bacteria was grown on Nutrient Agar (NA; Merck Germany) slant, incubated at $37^{\circ} \mathrm{C}$ for $24 \mathrm{~h}$, and kept at $4^{\circ} \mathrm{C}$ until further use. Bacterial suspension was prepared by inoculating one loopful of the 24-h old bacterial colonies into $10.0 \mathrm{ml}$ of sterilized distilled water. The inoculums size was adjusted to match the turbidity of McFarland 0.5 scale $\left(1 \times 10^{8} \mathrm{cells} / \mathrm{ml}\right)$ and diluted with sterilized distilled water to the inoculums size of $1 \times 10^{7}$ cells $/ \mathrm{ml}$.

Well diffusion assay: A screening assay using well diffusion [20] was carried out with some minor modifications. Nutrient agar plates (Merck, Germany) were inoculated by rubbing sterile cotton swabs that were dipped into bacterial suspensions (overnight) cultures grown at $37^{\circ} \mathrm{C}$ on nutrient agar and adjusted to $0.5 \mathrm{McFarland}$ in sterile saline) over the entire surface of the plate. After inoculation $8.2 \mathrm{~mm}$ diameter wells were cut into the surface of the agar using a sterile cork borer. 50 $\mu \mathrm{l}$ of test honey was added to each well. Plates were incubated at $30^{\circ} \mathrm{C}$ for $24 \mathrm{~h}$. A diffusion control of starch was used. Second step a mixture of starch-honey was prepared and incubated for one hour at $40^{\circ} \mathrm{C}$. After inoculation $8.2 \mathrm{~mm}$ diameter wells were cut into the surface of the agar using a sterile cork borer. $50 \mu \mathrm{l}$ of mixture (honey and starch) were added to each well. Zones of inhibition were measured using a Vernier caliper. The diameter of zones, including the diameter of the well, was recorded. Bioassay was performed in duplicate and repeated twice. The results were expressed in terms of the diameter of the inhibition zones: $<5.5 \mathrm{~mm}$, inactive; $5.5-9 \mathrm{~mm}$, very low activity; 9-12 $\mathrm{mm}$, low activity; $12-15 \mathrm{~mm}$, average activity; and $>15 \mathrm{~mm}$, high activity.

\section{Statistical analysis}

Each honey was analyzed in triplicate. Results are shown as mean values and standard deviation. Correlations were established using Pearson's correlation coefficient $(r)$ in bivariate linear correlations $(p<0.01)$. All statistical analyses were performed with the Statistica 7.0 software for Windows.

\section{Results and Discussion}

\section{Physicochemical parameters}

Table 1 shows the means, standard deviations and ranges of the various physicochemical parameters analyzed: glucose, fructose, Fructose/Glucose ratio, saccharose, maltose, diastase number and HMF content. Honey is mainly composed of the monosaccharides glucose and fructose. Our results show a mean glucose content of $27.56 \mathrm{~g} \%$ and a mean fructose content of $35.74 \mathrm{~g} \%$ (Table 1). It has been proposed that the proportion of fructose to glucose depends largely on the nectar source [21]. Also Molan [22] reported that the proportions of fructose and glucose are determined by the composition of the plant secretion. It has been reported that the average ratio of fructose to glucose contents is approximately 1.3 [23]. In our study, the ratio of fructose to glucose is between 1.14 and $1.44($ mean=1.3) (Table 1), which may have an effect on honey flavor given that fructose is sweeter than glucose. Also the ratio of fructose and glucose can be used as an indicator for the identification and classification of unifloral honeys [24-26]. Sucrose is present in six samples, ranging between 0.00 and $0.68 \%$ (Table 1 ) the content of sucrose in the all tested samples was in conformity with the limits established by the European Codex Honey Standards, which are $<5 \mathrm{~g} / 100 \mathrm{~g}$ for honeys in general and up to $10 \mathrm{~g} / 100 \mathrm{~g}$ for Citrus honeys [27]. A high sucrose concentration in honey usually reflects an early harvest because the sucrose has not been fully transformed into glucose and fructose by the action of invertase [28]. According to Da Costa Leite et al. [29], the reason for the variable levels of sucrose could be that a transglucosylation reaction is initiated by transference of the a-D-glucopyranosyl unit from sucrose to an acceptor molecule. Maltose was the most abundant disaccharide in honey constituting from 8.45 to $4.72 \mathrm{mg} / \mathrm{g}$ (Table 1). Maltose content in natural honey is generally less than $30 \mathrm{mg} / \mathrm{g}$ [30,31]. Maltose in some honeys originating from certain plants can be up to $50 \mathrm{mg} / \mathrm{g}[32,33]$. Literature data shows that high amounts of maltose may indicate adulteration of honey by sugar syrup or starch hydrolysate $[33,34]$. The content of hydroxymethylfurfural in honeys ranged from 3.8 to $78.4 \mathrm{mg} / \mathrm{kg}$ (Table 1). One of the samples (samples 1) showed levels of HMF higher than the allowed limits of $40 \mathrm{mg} / \mathrm{kg}$, which are indicative of temperature abuse during processing and/or bad storage practices. Several factors influence the levels of $\mathrm{HMF}$, such as temperature and time of heating, storage conditions, $\mathrm{pH}$ and floral source [35]. Diastase is a natural enzyme of honey. Its level depends upon geographic and floral origins of the product, as well as on its freshness. As with HMF, diastase activity can be used as indicative of aging and temperature abuse, but with precaution, since its variability has been higher, confirmed in several honeys [35]. The honey samples analyzed in the present work show a range of values, between 7.3 and 22.1 Schade units. One sample (H5) show values below 8 Schade units (Table 1).

The six honey samples were studied in terms of antibacterial activity were performed in duplicate. The differences in inhibition were observed for six types of honey sample (H1) has the largest inhibition with an average diameter of $32 \mathrm{~mm}$, followed by the sample ( $\mathrm{H} 2$ and $\mathrm{H} 3)$ in $(30 \mathrm{~mm}), \mathrm{H} 6(28 \mathrm{~mm}), \mathrm{H} 4(27 \mathrm{~mm})$ and finally the sample H5 $(25 \mathrm{~mm})$. No zone of inhibition was determined with starch alone (Figure 1). Antibiotic-resistant bacteria continue to be of major health concern world-wide. For all antibiotic classes, including the major lastresort drugs, resistance is increasing worldwide [36,37]. Consequently, scientific efforts have been made to study and develop new compounds to be used beyond conventional antibiotic therapy. For centuries, honey has been used as remedies and treatments of diseases. The antimicrobial activities of honey toward various pathogens have been widely investigated. The mechanism of honey antimicrobial activity is complex and might be attributed to the synergistic activity between its various potent biological ingredients such as phenolics and flavonoids [38-40]. Many factors influence the antibacterial activity of honey s such as the honey origin, bee species and extract preparation [41]. The variations in 
Citation: Ahmed M, Djebli N, Aissat S, Bacha S, Meslem A, et al. (2012) Synergistic Inhibition of Natural Honey and Potato Starch and their Correlation with Diastase Number and Sugar Content against Klebsiella pneumoniae ATCC 27736. Nat Prod Chem Res 1:102. doi:10.4172/2329-6836.1000102

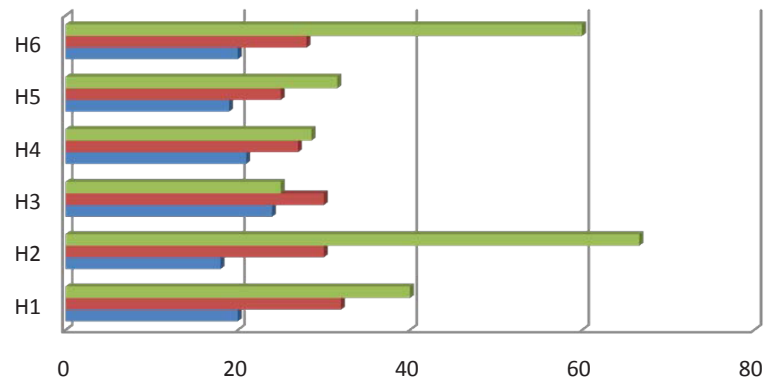

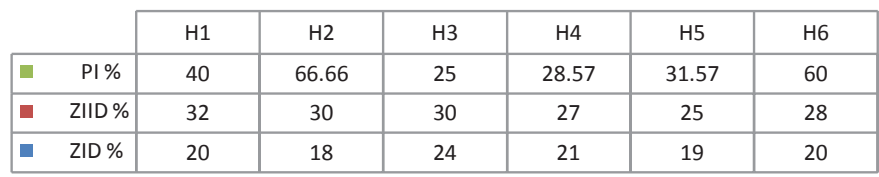

The differences in inhibition were observed of six natural honey

* PI\%:Percentage increase

* ZIID:Zone Inhibition IncreaseDiameter

* Zl:Zone Inhibition Diamater

Figure 1: Inhibition Zone Diameters of natural honey with potato starch against K. pneumoniae ATCC 27736 . zones: $<5.5 \mathrm{~mm}$, inactive; $5.5-9 \mathrm{~mm}$, very low activity; $9-12$ $\mathrm{mm}$, low activity; $12-15 \mathrm{~mm}$, average activity; and >15 mm, high activity.

\begin{tabular}{|c|c|c|c|c|c|c|}
\hline \multirow{2}{*}{$\begin{array}{l}\text { Physicochemical } \\
\text { parameters }\end{array}$} & H1 & $\mathrm{H} 2$ & H3 & H4 & H5 & $\mathrm{H} 6$ \\
\hline & Mean \pm DS & Mean \pm DS & Mean \pm DS & Mean \pm DS & Mean \pm DS & Mean \pm DS \\
\hline Glucose ( $\mathrm{g} / 100 \mathrm{~g}$ honey) & $26.37 \pm 2.14$ & $26.18 \pm 2.14$ & $25.78 \pm 2.14$ & $28.84 \pm 2.14$ & $27.24 \pm 2.14$ & $30.95 \pm 2.14$ \\
\hline $\begin{array}{c}\text { Fructose } \\
\text { (g/100 g honey) }\end{array}$ & $35.29 \pm 3.32$ & $37.81 \pm 3.32$ & $33.92 \pm 3.32$ & $36.84 \pm 3.32$ & $35.41 \pm 3.32$ & $35.18 \pm 3.32$ \\
\hline Fructose/Glucose ratio & 1.34 & 1.44 & 1.32 & 1.28 & 1.30 & 1.14 \\
\hline $\begin{array}{c}\text { Sucrose } \\
\text { (g/100 g honey) }\end{array}$ & $0.00 \pm 0.10$ & $0.54 \pm 0.10$ & $0.68 \pm 0.10$ & $1.41 \pm 0.10$ & $1.22 \pm 0.10$ & $0.00 \pm 0.10$ \\
\hline $\begin{array}{c}\text { Maltose } \\
\text { (g/100 g honey) }\end{array}$ & $4.72 \pm 1.32$ & $7.13 \pm 1.32$ & $8.45 \pm 1.32$ & $7.01 \pm 1.32$ & $7.01 \pm 1.32$ & $7.10 \pm 1.32$ \\
\hline $\begin{array}{l}\mathrm{HMF} \\
\mathrm{mg} / \mathrm{kg}\end{array}$ & $78.4 \pm 1.9$ & $28.2 \pm 1.9$ & $11.1 \pm 1.9$ & $9.8 \pm 1.9$ & $7.6 \pm 1.9$ & $3.8 \pm 1.9$ \\
\hline $\begin{array}{c}\text { Diastase activity (Schade } \\
\text { Number) }\end{array}$ & $15.1 \pm 2.8$ & $23.5 \pm 2.8$ & $11 \pm 2.8$ & $26 \pm 2.8$ & $7.3 \pm 2.8$ & $16.4 \pm 2.8$ \\
\hline
\end{tabular}

Table 1: Physicochemical parameters (glucose, fructose, fructose/glucose ratio, Sucrose, hydroxymethylfurfural content and diastase activity) of the analyzed honey samples (mean \pm standard deviation, $\mathrm{n}=3$ ).

\begin{tabular}{|c|c|c|c|c|c|c|c|c|}
\hline & Glucose & Fructose & Fructose/Glucose & Sucrose & Maltose & HMF & Diastase & PI \% \\
\hline $\mathrm{PI} \%$ & $0.265^{*}$ & $0.514^{*}$ & 0.050 & $-0.58^{*}$ & -0.15 & 0.086 & $0.378^{*}$ & 1.00 \\
\hline
\end{tabular}

Table 2: Correlation matrix (Pearson's correlation coefficients) for quantitative determinations in the natural honey.

antibacterial activity of honey can be related to the amount of hydrogen peroxide and the presence of additional antibacterial components derived from the nectar source [6]. Honey is an extremely varying and complex mixture of sugars and other minor components. Fructose is the most dominant sugar followed by glucose in almost all types of honey. The use of sugar for the treatment of infected wounds was investigated in in vitro experiments with bacteria pathogenic to humans, such as Escherichia coli, Pseudomonas aeruginosa, Klebsiella pneumoniae, and Staphylococcus aureus [42]. Herszage et al. [43] followed the evolution of bacterial flora present in various infected wounds being treated with sugar. Bacteria initially present included, Klebsiella sp. disappeared during the first days of sugar treatment. Recent experimental finding indicated that the amylase present in honey increases the osmotic effect in the media by increasing the amount of sugars and consequently increasing the antimicrobial activity $[8,44-46]$. Synergism is a positive interaction created when two agents combined and exert an inhibitory effect (on the targeted organisms) that is greater than the sum of their individual effects. In present study honey collected from Algeria has a potent antibacterial activity against $K$. pneumoniae, and showed synergistic properties when they were mixed with potato starch. In our study, the addition of starch potato honey showed a significant increase in the inhibition zone for honey studied against the strain. Amylase present in honey was expected to split starch chains into randomly produced dextrin and maltose and probably increases the osmotic effect in the well by increasing the amount of sugar and consequently increases the antibacterial activity [45]. Previous studies also show that the addition ginger starch to honey could contribute to reducing the quantity of honey to be used without losing the expected effect [44-46].

Positive correlation has been established between the zone increase of inhibition and the fructose $(\mathrm{r}=0.514)$, glucose $(\mathrm{r}=0.265)$ and Diastase number $(r=0.378)$. Negative correlation has been established between the zone increase and the sucrose $(\mathrm{r}=0.378)$ (Table 2).

The major value of this study is the demonstration that the combination of honey with a potato starch primarily results in synergy. In summary, we found that, when used in combination, the six natural honeys and potato starch exhibited strong synergy in inhibiting the growth of $K$. pneumoniae. This is the first study to report antibacterial synergism for honey and potato starch. 
Citation: Ahmed M, Djebli N, Aissat S, Bacha S, Meslem A, et al. (2012) Synergistic Inhibition of Natural Honey and Potato Starch and their Correlation with Diastase Number and Sugar Content against Klebsiella pneumoniae ATCC 27736. Nat Prod Chem Res 1:102. doi:10.4172/2329-6836.1000102

\section{References}

1. Podschu R, Ullmann U (1998) Klebsiella spp. as nosocomial pathogens: Epidemiology, Taxonomy, Typing Methods and Pathogenicity factors. Clin Microbiol Rev 11: 589-603.

2. Steinhauer BW, Eickhoff TC, Kiscak JW, Finland M (1965) The KlebsiellaEnterobacter-Serratia division. Clinical and epidemiologic characteristics. Ann Intern Med 65: 1180-1194.

3. Arlet G, Rouveau M, Casin I, Bouvet PJ, Lagrange PH, et al. (1994) Molecular epidemiology of Klebsiella pneumoniae strains that produce SHV-4- $\beta$ lactamase and which were isolated in 14 French hospitals. J Clin Microbiol 32 2553-2558.

4. Meier C, Oelschlaeger TA, Merkert H, Korhonen TK, Hacker J (1996) Ability of Escherichia coli isolates that cause meningitis in newborns to invade epithelia and endothelial cells. Infect Immun 64: 2391-2399.

5. Butler MS (2004) The Role of Natural Product Chemistry in Drug Discovery. $J$ Nat Prod 67: 2141-2153.

6. AL-Waili N, Al-Ghamdi A, Ansari MJ, Al-Attal Y, Salom K (2012) Synergistic Effects of Honey and Propolis toward Drug Multi-Resistant Staphylococcus aureus, Escherichia coli and Candida albicans Isolates in Single and Polymicrobial Cultures. Int J Med Sci 9: 793-800

7. Ahmed M, Djebli N, Meslem A, Aissat S, Bacha S, et al. (2012) Antiradical Activity and Total Phenolics of Algerian Honeys and Antibacterial Effect Against Gram-Negative Bacteria. J Microb Biochem Technol 4: 7.

8. Ahmed M, Djebli N, Aissat S, Douichene S (2012) The Relationship between fructose, glucose and maltose content with Diastase number and antiPseudomonal activity of natural honey combined with potato starch. Organic Chem Curr Res 1: 6 .

9. Moussa A, Noureddine D, Mohamed HS, Abdelmelek M, Saad A (2012) Antibacterial activity of various honey types of Algeria against Pathogenic Gram-Positive cocci: Staphylococcus aureus and Streptococcus pyogenes. Asian Pac J Trop Med 5: 773-776.

10. Ahmed M, Djebli N, Meslem A, Aissat S (2012) Antibacterial activity of various honey types of Algeria against Pathogenic Gram-Negative Bacilli: Escherichia coli and Pseudomonas aeruginosa. Asian Pac J Trop Disease 211-214.

11. Saxena S, Gautam S, Sharma A (2010) Physical, biochemical and antioxidant properties of some Indian honeys. Food Chem 118: 391-397.

12. Huidobro JF, Santana FJ, Sanchez MP, Sancho MT, Muniategui S, et al. (1995) Diastase, invertase and $\beta$-glucosidase activities in fresh honey from north-west Spain. J Api Res 34: 39-44.

13. Stadelmeier M, Bergner KG (1986) Proteine des bienenhonigs. VII Eigenschaften und herkunft der honigamylase. Z Lebensm Unters Forsch 182: 196-199.

14. Wang J, Li QX (2011) Chemical Composition, Characterization and Differentiation of Honey Botanical and Geographical Origins. Adv Food Nutr Res 62: 89-137.

15. Nafea EA, Moselhy WA, Fawzy AM (2011) Does the HMF value affect the Antibacterial activity of the Bee Honey? Egypt Acad J biolog Sci 4: 13-19.

16. EU Directive /110/2001 of 02/12/2001 (L 10/47).

17. Winkler O (1955) Beitrag zum Nachweis und zur Bestimmung von Oxymethylfurfural in Honig und Kunsthonig. Zeitschrift fur Lebensmitte Untersuchung und Forshung 102: 161-167.

18. Schade JE, Marsh GL, Eckert JE (1958) Diastatic activity and hydroxymethylfurfural in honey and their usefulness in detecting heat adulteration. Food Research 23: 446-463.

19. Bogdanov S, Martin P, Lullmann C, European Honey Commision, Borneck R (1997) Harmonised methods of the European Honey Commission. Apidologie.

20. al Somal N, Coley KE, Molan PC, Hancock BM (1994) Susceptibility of Helicobacter pylori to the antibacterial activity of manuka honey. J R Soc Med 87: 9-12.

21. Anklam E (1998) A review of the analytical methods to determine the geographical and botanical origin of honey. Food Chem 63: 549-562.

22. Molan PC (1996) Honey for the treatment of infection. Bee-Informed 3: 6-7.

23. Mateo R, Bosch-Reig F (1997) Sugar profiles of Spanish unifloral honeys. Food Chem 60: 33-41.
24. Low NH, Nelson DL, Sporns P (1988) Carbohydrate analysis of western Canadian honeys and their nectar sources to determine the origin of honey oligosaccharides. J Apic Res 27: 245-251.

25. Persano Oddo L, Piro R (2004) Main European unifloral honeys: descriptive sheets. Apidologie 35: S38-S81.

26. Persano LO, Piazza MG, Sabatini AG, Accorti M (1995) Characterization of unifloral honeys. Apidologie 26: 453-465

27. Codex Alimentarius Commission Standard (2001) 24th Session, July 2001 adopting the draft revised standard for honey. Alinorm 01/25, Appendix II: 22 24.

28. Kuçuk M, Kolaili S, Karaoglu S, Ulusoy E, Baltaci C, et al. (2007) Biological activities and chemical composition of three honeys of different types from Anatolia. Food Chem 100: 526-534

29. Da Costa Leite JM, Trugo LC, Costa LSM, Quinteiro LMC, Barth OM, et al. (2000). Determination of oligosaccharides in Brazilian honeys of different botanical origin. Food Chem 70: 93-98.

30. Cotte JF, Casabianca H, Chardon S, Lheritier J, Grenier-Loustalot MF (2003) Application of carbohydrate analysis to verify honey authenticity. J Chromatogr A 1021: 145-155.

31. Joshi SR, Pechhacker H, Willam A, Von der ohe W (2000) Physicochemical characteristics of Apis dorsata, A. cerana and A. mellifera honey from Chitwan district, Nepal. Apidologie 31: 367-375.

32. Costa LSM, Albuquerque MLS, Trugob LC, Quinteiro LMC, Barth OM, et al. (1999) Determination of non-volatile compounds of different botanical origin Brazilian honeys. Food Chem 65: 347-352.

33. Devillers J, Morlot M, Pham-Delegue MH, Dore JC (2004). Classification of monofloral honeys based on their quality control data. Food Chem 86: 305-312.

34. Horvath K, Molnar-Perl I (1997) Simultaneous quantitation of mono-, di- and trisaccharides by GC-MS of their TMS ether oxime derivatives: II. In honey. Chromatographia 45: 328-335.

35. Fallico B, Arena E, Verzera A, Zappala M (2006) The European food legislation and its impact on honey sector. Accredit Qual Assur 11: 49-54.

36. Walsh C (2003) Antibiotics: actions, origins, resistance. American Society for Microbiology (ASM) Press, Washington.

37. Levy SB, Marshall B (2004) Antibacterial resistance worldwide: causes, challenges and responses. Nat Med 10: S122-S129.

38. Ulusoy E, Kolayli S, Sarikaya AO (2010) Antioxidant and antimicrobial activity of different floral origin honeys from turkiye. J Food Biochem 34: 321-335.

39. Al-mamary M, Al-meeri A, Al-habori M (2002) Antioxidant activities and total phenolics of different types of honey. Nutr Res 22: 1041-1047.

40. Snowdon JA, Cliver DO (1996) Microorganisms in honey. Int J Food Microbio 31: 1-26.

41. Manyi-Loh CE, Clarke AM, Ndipa RN (2012) Detection of Phytoconstituents in Column Fractions of n-Hexane Extract of Goldcrest Honey Exhibiting AntiHelicobacter pylori Activity. Arch Med Res 43: 197-204.

42. Chirife J, Herszage L, Joseph A, Kohn ES (1983) In vitro Study of Bacteria Growth Inhibition in Concentrated Sugar Solutions: Microbiological Basis for the Use of Sugar in Treating Infected Wounds. Antimicrob Agents Chemother 23: $766-773$

43. Herszage L, Montenegro JR, Joseph AL (1980) Tratamiento de las heridas supuradas con azficar granulado comercial. Bol Trab Soc Argent Cir 41: 315330

44. Ahmed M, Djebli N, Aissat S, Aggad H, Boucif A (2011) Antifungal Activity of a Combination of Algeria Honey and Starch of Ginger Against Aspergillus niger. Int J Microbiol Res 2: 263-266.

45. Ahmed M, Aissat S, Djebli N, Boulkaboul A, Abdelmalek M, et al. (2011) The Influence of Starch of Ginger on the Antibacterial Activity of Honey of Different Types from Algeria against Escherichia coli and Staphylococcus aureus. Int $\mathrm{J}$ Microbiol Res 2: 258-262.

46. Ahmed M, Djebli N, Hammoudi SM, Aissat S, Akila B, et al. (2012) Additive potential of ginger starch on antifungal potency of honey against Candida albicans. Asia Pacific J Tropical Biomed 2: 253-255. 